\title{
Attitudes and Beliefs About Emergency Contraception Among Patients at Academic Family Medicine Clinics
}

\author{
Jobn W. Campbell III, MD \\ Stephen C. Busby, MD \\ Terrence E. Steyer, MD \\ Trident - Medical University of South Car- \\ olina Family Medicine Residency Program, \\ Charleston, South Carolina
}

\begin{abstract}
PURPOSE The possible mechanisms of action of emergency contraception (EC) include preventing ovulation, fertilization, or implantation of an embryo. Differences in the use of terminology between medical personnel and the general public could be misleading to patients who would use EC. This cross-sectional survey evaluated women's beliefs regarding pregnancy and EC's possible mechanisms of actions.

METHODS An anonymous questionnaire was developed and pilot tested for an appropriate reading level and ease of analysis. It collected information on demographics and beliefs about pregnancy and EC. During an 8-week period, the questionnaire was given to a convenience sample of female patients aged 18 to 50 years visiting 2 academic family medicine clinics in the southeastern United States. Descriptive statistics and logistic regression models were used for analysis.

RESULTS A total of 178 women completed questionnaires. Nearly one-half (47\%) of respondents believed that pregnancy begins with fertilization; however, less than one-third (30\%) believed that life begins with fertilization. Thirty-eight percent of respondents stated that they would use EC only if they believed it worked before fertilization or implantation. Generally similar proportions thought that EC works before fertilization (24\%) and before implantation (36\%), or were unsure about when it works (34\%). Younger age was associated with higher odds of believing that EC works before fertilization; none of the other demographic factors studied conferred either higher or lower odds.
\end{abstract}

CONCLUSIONS Many women are uninformed about the possible mechanisms of action of EC, and we found no reliable predictors for those who were better informed. This study raises questions regarding women's understanding of EC and demonstrates the need to better educate them about its possible mechanisms of action.

Ann Fam Med 2008;6(suppl 1):s23-s27. DOI: 10.1370/afm.744.

\section{INTRODUCTION}

E mergency contraception (EC) is defined as any method women can use after intercourse to prevent pregnancy. ${ }^{1}$ The differing methods of EC include the use of intrauterine devices and hormone pills, such as the over-the-counter hormonal method known as Plan B. ${ }^{2}$ Several mechanisms of action have been suggested in the literature for the effectiveness of EC. One possible mechanism of action is the inhibition or delay of ovulation. ${ }^{3-6}$ A second possible mechanism is a histologic or biochemical alteration of the endometrium that impairs endometrial receptivity to implantation of a fertilized egg., ${ }^{4,-13}$ Other studies, however, dispute this claim and suggest that there is no effect on the endometrium. ${ }^{3,14,15}$ Despite the other suggested mechanisms of action of EC, prevention of implantation is accepted as a possible mechanism and is listed as such in major drug databases ${ }^{16}$ and the Plan B package insert. ${ }^{17}$ 


\section{Figure 1. Questionnaire.}

Please read the following explanation of terms.

After intercourse, if conditions are right, a sperm and egg can join within the female reproductive tract to form one new genetically unique cell. This cell divides and grows to form a many-celled organism as it progresses toward the womb. Again, if conditions are right, 6 to 7 days after forming, this organism attaches to the inner wall of the womb. The point at which this happens is known as implantation. Around 3 weeks after sperm and egg join, the organism's newly formed heart starts beating. Normal pregnancy lasts 9 months and is divided equally into first, second, and third trimesters.

Answer the following questions to the best of your ability by circling one option.

1. I understand conception to be the point at which:
A. Sperm and egg join within the female reproductive tract.
B. Implantation occurs.
C. The heart starts beating.
B. Implantation occurs.
C. The heart starts beating.
D. Does not matter to me when it works.
E. Unsure
F. Other:

D. Unsure

E. Other:

2. Pregnancy begins when
A. Sperm and egg join within the emale reproductive tract.
B. Implantation occurs.
C. The heart starts beating.
D. Unsure
E. Other:

3. Life begins when

A. Sperm and egg join within the female reproductive tract.

B. Implantation occurs.

C. The heart starts beating.

D. Birth occurs.

E. Unsure

F. Other:

4. I would consider it an abortion to stop a pregnancy from progressing any time after
A. Sperm and egg join within the female reproductive tract.
B. Implantation occurs.
C. The heart starts beating.
D. Unsure
E. Other:

5. I would consider it wrong to stop a pregnancy from progressing any time after

A. Sperm and egg join within the female reproductive tract.

B. Implantation occurs.

C. The heart starts beating.

D. First trimester starts.

E. Second trimester starts.

F. Third trimester starts.

G. Any time during pregnancy is okay.

H. Unsure

I. Other:

6. It is my understanding that emergency contraception will only work before

A. Sperm and egg join within the female reproductive tract.

B. Implantation occurs.

C. The heart starts beating.

D. Unsure

E. Other:
7. I would use emergency contraception only if it works before

A. Sperm and egg join within the female reproductive tract.

8. I would use emergency contraception A. Only if my doctor told me it would not cause an abortion.

B. Only if my doctor told me there was only a small chance it could cause an abortion.

C. Regardless of whether my doctor said there was a chance it could cause an abortion.

D. Unsure

E. Would never use.

Please answer the following confidential questions about yourself.

1. Age:

2. Gender:

A. Male

B. Female

3. Race:
A. Black
B. White
C. Asian
D. Hispanic
E. Native American
F. Other

4. Highest level of education:

A. Less than high school

B. High school graduate

C. Some college

D. College graduate

E. Some postgraduate studies

F. Postgraduate degree

G. Other

5. In which category would you say your annual household income falls?

A. Less than $\$ 15,000$

B. $\$ 15,001-\$ 25,000$

C. $\$ 25,001-\$ 40,000$

D. $\$ 40,001-\$ 60,000$

E. More than $\$ 60,000$

6. Do you currently have health insurance?

A. Yes

B. No

7. If yes, what type?

A. Medicare

B. Medicaid

C. Fee for service (Blue Cross/ Blue Shield)

D. HMO/PPO (MUSC Options,

HMO Blue, Companion)

E. None

F. Other:
8. What is your religious preference?

A. Christian (which denomination?)

B. Jewish

C. Muslim

D. No religion

E. Other religion:

9. How strong are your religious beliefs?
A. Very strong
B. Moderate
C. Not very strong
D. Not at all

10. How often do you usually attend religious services?

A. At least twice a week

B. Weekly

C. Nearly every week

D. About once a month

E. A few times a year

F. Rarely

G. None

11. Marital status:

A. Married

B. Single

C. Significant relationship

D. Divorced

E. Widowed

F. Other

12. Number of children:
A. 1
B. 2
C. 3
D. 4 or more
E. None

13. Are you presently sexually active?
A. Yes

B. No

14. What type of contraception do you use on a regular basis? (circle all that apply)

A. Oral contraceptive pills

B. Condoms

C. Spermicide

D. Diaphragm

E. IUD

F. None

G. Other:

15. Have you ever used emergency contraception (Plan B, Preven, etc)?

A. Yes

B. No

$\mathrm{HMO}=$ health maintenance organization; PPO $=$ preferred provider organization; MUSC $=$ Medical University of South Carolina; IUD $=$ intrauterine device 
Patient understanding of the terminology surrounding the mechanisms of action of EC has not been previously studied. Differences in the understanding of terminology between patients and physicians could raise questions regarding the quality of informed consent when patients are told that EC will not act as an abortifacient and will not work once a woman is pregnant. One study looked at the acceptance and use of EC with a standardized counseling intervention and found that one-half of the women who received counseling accepted a prescription for EC in advance of a possible need for EC. ${ }^{18}$ This counseling did not change their overall use of EC, however.

Additionally, the topic of EC involves moral implications for patients concerning their beliefs about the beginning of life. A public opinion poll of more than 15,000 people showed that almost $50 \%$ of the population believe that life begins at conception, or when the sperm and egg join. ${ }^{19}$

In this study, we investigated women's beliefs surrounding conception and the beginning of pregnancy. We also evaluated women's willingness to use EC based on its possible mechanisms of action.

\section{METHODS}

This cross-sectional survey took place in 2 academic family medicine clinics in the southeastern United States. One clinic predominately serves an urban population and is staffed by medical school faculty. The other clinic is in a suburban area and is staffed primarily by family medicine residents. The survey was conducted during an 8-week period (February through April and October through November) in 2006.

We developed and pilot tested a questionnaire for an appropriate (6th-grade) reading level and for ease of analysis. The questionnaire (Figure 1) was approved as exempt research by the Institutional Review Board at the Medical University of South Carolina. It was administered anonymously to a convenience sample of female patients by the clinic registration staff. Participation was restricted to women aged 18 to 50 years.

Some questions asked patients about their beliefs regarding the beginning of life, conception, and pregnancy. Other questions were designed to gain insight into patients' understanding of the possible mechanisms of action of EC. The questionnaire also requested demographic information, including respondents' age, sex, race, education, income, marital status, children, religious affiliation, strength of religious belief, and any use of contraception.

The data were analyzed with SAS software (SAS Institute, Cary, North Carolina) and by the use of descriptive statistics and logistic regression analysis.

\section{RESULTS}

A total of 178 women completed questionnaires. The demographic characteristics of the respondents are shown in Table 1. Compared with clinic patients overall, respondents were younger but of similar races.

Table 2 shows the responses to the questions about conception, pregnancy, and EC. The majority (81\%) of respondents agreed that conception occurs when the sperm and egg join. The respondents' beliefs were split, however, regarding when pregnancy begins and when life begins; nearly one-half (47\%) believed that pregnancy begins with fertilization, but less than one-third (30\%) believed that life begins at that point. There was no majority belief on when a respondent would use EC in the process of fetal development. Thirty-eight percent of respondents stated that they would use EC only if they believed it worked before fertilization or implantation, and a large proportion (42\%) of respondents were unsure of how their potential use of EC would change based on a physician's comments about when it worked during fetal development.

Table 3 shows the results from the logistic regression analysis. Women with incomes of less than $\$ 40,000$ were more likely to believe that life begins at the joining of sperm and egg than women with higher incomes. Additionally, women aged 25 years or younger were more likely to think that EC works before the egg and sperm join than older women. There were no significant differences in the perception

\section{Table 1. Demographic Characteristics of Survey} Respondents $(\mathrm{N}=178)$

\begin{tabular}{lc}
\hline Characteristic & No. (\%) of Respondents \\
\hline Age, years & $38(21.3)$ \\
$18-25$ & $64(36.0)$ \\
$26-35$ & $61(34.3)$ \\
$36-45$ & $15(8.4)$ \\
$46-50$ & \\
Race & $73(41.0)$ \\
Black & $96(53.9)$ \\
White & $9(5.1)$ \\
Other & \\
Education level & $56(31.4)$ \\
High school graduate or less & $64(36.0)$ \\
Some college & $58(32.6)$ \\
College graduate or more & \\
Yearly income & $87(48.9)$ \\
$<\$ 25,000$ & $54(30.3)$ \\
$\$ 25,000-\$ 40,000$ & $37(20.8)$ \\
$>\$ 40,000$ & $86(48.3)$ \\
Strength of religious beliefs & $68(38.2)$ \\
Very strong & $24(13.5)$ \\
Moderate & \\
Little or none &
\end{tabular}


Table 2. Respondents' Answers to Questions on Pregnancy and Emergency Contraception ( $\mathrm{N}=178)$

\begin{tabular}{lclc}
\hline Question & $\begin{array}{c}\text { No. (\%) of } \\
\text { Respondents }\end{array}$ & Question & $\begin{array}{c}\text { No. (\%) of } \\
\text { Respondents }\end{array}$ \\
\hline Conception is the point when ... & & I would only use EC if it works ... & $36(20)$ \\
Sperm and egg join & $144(81)$ & Before sperm and egg join & $32(18)$ \\
Implantation occurs & $30(17)$ & Before implantation occurs & $18(10)$ \\
The heart starts beating & $4(2)$ & Before heart starts beating & $32(18)$ \\
Pregnancy begins when ... & & Does not matter when & $20(11)$ \\
Sperm and egg join & $84(47)$ & Would never use & $40(22)$ \\
Implantation occurs & $78(44)$ & Unsure & $60(34)$ \\
The heart starts beating & $14(8)$ & I would use EC only if my doctor told me ... & $6(3)$ \\
Unsure & $2(1)$ & It would not cause an abortion & $27(15)$ \\
Life begins when ... & There was a small chance it could cause & $11(6)$ \\
Sperm and egg join & an abortion & $74(42)$ \\
Implantation occurs & $54(30)$ & Regardless of what my doctor said & Would never use \\
The heart starts beating & $22(12)$ & Unsure & \\
Birth occurs & $84(47)$ & & \\
Emergency contraception works $\ldots$ & $18(10)$ & & \\
Before sperm and egg join & $43(24)$ & & \\
Before implantation occurs & $64(36)$ & & \\
Before heart starts beating & $11(6)$ & $60(34)$ & \\
Unsure & & & \\
\hline Note: Percentages may not add to $100 \%$ because of rounding. & & \\
EC = emergency contraception. & & & \\
\hline
\end{tabular}

of abortion or the use of EC based on age, race, income, education, or strength of religious beliefs (data not shown).

\section{DISCUSSION}

Many of the participants in this study indicated that use of EC would be acceptable to them. Responses suggested, however, that the majority of women surveyed did not know that one possible mechanism of action of EC is to prevent implantation of a fertilized ovum. Although 30\% of respondents believed that life begins at fertilization of the egg by sperm, respondents had different beliefs regarding their potential use of EC. These results suggest that women may not fully understand the possible mechanisms of action of EC. This lack of understanding may especially be true for younger women, who may be more likely to use EC. ${ }^{20}$

Debate over the availability of EC has been quite intensive. Its use by prescription led to a call by pharmacists for the concept of "ethical refusal," which would allow them to not fill prescriptions if doing so violated their moral beliefs. Some pharmacists went so far as to hold the prescription so that it could not be taken to another pharmacy to be filled. ${ }^{21}$

\section{Table 3. Logistic Regression Analysis of Beliefs Regarding Beginning of Life and Emergency Contraception}

\begin{tabular}{|c|c|c|}
\hline Characteristic & $\begin{array}{l}\text { Life Begins When } \\
\text { Egg and Sperm Join } \\
\text { Odds Ratio }(95 \% \mathrm{Cl})\end{array}$ & $\begin{array}{l}\text { EC Works Before Egg } \\
\text { and Sperm Join } \\
\text { Odds Ratio }(95 \% \mathrm{Cl})\end{array}$ \\
\hline \multicolumn{3}{|l|}{ Age, years } \\
\hline $18-25$ & $1.04(0.20-5.50)$ & $5.79(1.20-27.8)$ \\
\hline $26-35$ & $1.16(0.26-5.20)$ & $3.40(0.96-12.1)$ \\
\hline $36-45$ & $1.75(0.39-7.74)$ & $2.24(0.67-7.48)$ \\
\hline $46-50$ & 1.00 & 1.00 \\
\hline \multicolumn{3}{|l|}{ Race } \\
\hline Black & $1.51(0.31-7.42)$ & $0.57(0.08-4.24)$ \\
\hline White & $1.14(0.23-5.58)$ & $1.41(0.18-11.2)$ \\
\hline Other & 1.00 & 1.00 \\
\hline \multicolumn{3}{|l|}{ Education } \\
\hline $\begin{array}{l}\text { High school graduate } \\
\text { or lower }\end{array}$ & $1.06(0.41-2.77)$ & $1.87(0.71-4.89)$ \\
\hline Some college & $1.16(0.46-2.95)$ & $2.67(0.92-7.78)$ \\
\hline $\begin{array}{l}\text { College graduate } \\
\text { or more }\end{array}$ & 1.00 & 1.00 \\
\hline \multicolumn{3}{|l|}{ Yearly income } \\
\hline$<\$ 25,000$ & $7.73(2.71-22.0)$ & $0.41(0.12-1.43)$ \\
\hline$\$ 25,000-\$ 40,000$ & $4.48(1.57-12.9)$ & $0.39(0.12-1.24)$ \\
\hline$>\$ 40,000$ & 1.00 & 1.00 \\
\hline \multicolumn{3}{|l|}{$\begin{array}{l}\text { Strength of religious } \\
\text { beliefs }\end{array}$} \\
\hline Very strong & $0.60(0.18-1.94)$ & $0.50(0.11-2.40)$ \\
\hline Moderate & $1.85(0.59-5.77)$ & $0.78(0.17-3.50)$ \\
\hline Little or none & 1.00 & 1.00 \\
\hline
\end{tabular}


In addition, when the Food and Drug Administration (FDA) considered making this an over-the-counter product, a high-level FDA staffer resigned citing the prolonged length of time the product was taking to reach pharmacy shelves because of moral objections of some political entities. ${ }^{22}$ Our results are congruent with this controversy and reflect the moral debate currently occurring in the United States regarding various methods of abortion.

There are limitations to this study. First, we interviewed only women between the ages of 18 and 50 years who sought medical care in a family medicine office. Women in the general public or women who have used $\mathrm{EC}$ in the past may have different perspectives. Teenagers may also have different views but were excluded from this study because of concerns about informed consent by the institutional review board. We do not know the total number of questionnaires distributed and therefore cannot assess the response rate or potential responder bias. Second, the questionnaire was not used previously and was not tested for intrarater reliability. This shortcoming is evidenced by the different percentages of women stating they would never use EC when asked in separate questions. Although our instrument was pilot tested for readability, the development of a more reliable instrument may have yielded different results.

In conclusion, these results raise questions regarding patients' understanding of issues surrounding EC. Physicians and pharmacists should be careful when discussing contraception, as patients' beliefs differ greatly when discussing this issue. There is also the potential for misunderstanding the possible mechanisms of action of $\mathrm{EC}_{i}$ therefore, more appropriate consent processes and patient education materials should be developed so that women can feel confident that their use of $\mathrm{EC}$ is consistent with their moral beliefs.

To read or post commentaries in response to this article, see it online at http://www.annfammed.org/cgi/content/full/6/suppl_1/s23.

Key words: Emergency contraception; postcoital contraceptives; Plan B; morning-after pill; pharmacology: mechanism of action; unwanted pregnancies; decision making; informed consent; patient education

Submitted March 5, 2007; submitted, revised, July 20, 2007; accepted August 2, 2007.

A version of this paper was presented at the Hickory Knob Family Medicine Research Symposium, April 2006, McCormic, South Carilina; and at the North American Primary Care Research Group, October 2006, Tucson, Arizona.

\section{References}

1. Consensus statement on emergency contraception. Contraception. 1995;52(4):211-213.

2. Pruitt SL, Dolan Mullen P. Contraception or abortion: inaccurate descriptions of emergency contraception in newspaper articles, 1992-2002. Contraception. 2005;71(1):14-21.
3. Swahn ML, Westlund P, Johannisson E, Bygdeman M. Effect of postcoital contraceptive methods on the endometrium and the menstrual cycle. Acta Obstet Gynecol Scand. 1996;75(8):738-744.

4. Ling WY, Robichaud A, Zayid I, Wrixon W, MacLeod SC. Mode of action of dl-norgestrel and ethinylestradiol combination in postcoital contraception. Fertil Steril. 1979;32(3):297-302.

5. Rowlands S, Kubba AA, Guillebaud J, Bounds W. A possible mechanism of action of danazol and an ethinylestradiol/norgestrel combination used as postcoital contraceptive agents. Contraception. 1986;33(6):539-545.

6. Croxatto HB, Fuentalba B, Brache V, et al. Effects of the Yuzpe regimen, given during the follicular phase, on ovarian function. Contraception. 2002;65(5):121-128.

7. Kubba AA, White JO, Guillebaud J, Elder MG. The biochemistry of human endometrium after two regimens of postcoital contraception: a dl norgestrel/ ethinylestradiol combination or danazol. Fertil Steril. 1986;45(4):512-516.

8. Ling WY, Wrixon W, Zayid I, Acorn T, Popat R, Wilson E. Mode of action of dl-norgestrel and ethinylestradiol combination in postcoital contraception. II. Effect of postovulatory administration on ovarian function and endometrium. Fertil Steril. 1983;39(3):292-297.

9. Yuzpe AA, Thurlow HJ, Ramzy I, Leyshon JI. Post coital contraception-a pilot study. J Reprod Med. 1974;13(2):53-58.

10. Kahlenborn C, Stanford JB, Larimore WL. Postfertilization effect of hormonal emergency contraception. Ann Pharmacother. 2002;36(3):465-470.

11. Trussell J, Raymond EG. Statistical evidence about the mechanism of action of the Yuzpe regimen of emergency contraception. Obstet Gynecol. 1999;93(5 Pt 2):872-876.

12. Durand M, del Carmen Cravioto M, Raymond EG, et al. The mechanism of action of short term levonorgestrel administration in emergency contraception. Contraception. 2001;64(4):227-234.

13. Marions L, Hultenby K, Lindell I, Sun X, Stabi B, Gemzell Danielsson $\mathrm{K}$. Emergency contraception with mifepristone and levonorgestrel: mechanism of action. Obstet Gynecol. 2002;100(1):65-71.

14. Taskin O, Brown RW, Young DC, Poindexter AN, Wiehle RD. High doses of oral contraceptives do not alter endometrial al and amb3 integrins in the late implantation window. Fertil Steril. 1994;61(5):850-855.

15. Raymond EG, Lovely LP, Chen-Mok M, Sepp M, Kurman RJ, Lessey BA. Effect of the Yuzpe regimen of emergency contraception on markers of endometrial receptivity. Hum Reprod. 2000;15(11):2351-2355.

16. MICROMEDEX Healthcare Series: DRUGDEX Drug Point. Levonorgestrel. http://www.thomsonhc.com/hcs/librarian/ND_PR/Main/SBK/2/ PFPUI/sV1291P1GPF3n1/ND_PG/PRIH/CS/86A13B/ND_T/HCS/ND_P/ Main/DUPLICATIONSHIELDSYNC/410FA3/ND_B/HCS/PFActionld/hcs. common.RetrieveDocumentCommon/Docld/337200/ContentSetld/42/ SearchTerm/Levonorgestrel\%20/S. Accessed: February 20, 2007.

17. Plan B. Prescribing information [package insert]. http://www. go2planb.com/ForConsumers/Resources/References.aspx. Accessed: February 20, 2007.

18. Petersen R, Albright JB, Garrett JM, Curtis KM. Acceptance and use of emergency contraception with standardized counseling intervention: results of a randomized controlled trial. Contraception. 2007;75(2):119-125.

19. Harris Interactive Poll. When does life begin? Fundamental question divides pro-life from pro-choice Americans. April 4-10, 2000. http://www.harrisinteractive.com/news/allnewsbydate. asp?NewsID =94. Accessed: February 20, 2007.

20. As-Sanie S, Gantt A, Rosenthal MS. Pregnancy prevention in adolescents. Am Fam Physician. 2004;70(8):1517-1524.

21. American College of Clinical Pharmacists. Position statement: prerogative of a pharmacist to decline to provide professional services based on conscience. http://www.accp.com/position/pos31_200508. pdf. Accessed: February 20, 2007.

22. Burstein PD. A sad day for science at the FDA. N Engl J Med. 2005 : 353(24):2619-2621; author reply 2619-2621. 